has received. Sir William Armstrong's view is that the promoters 'have a very sound claim upon the Government, considering how liberally the scheme has been supported locally. I think it would be a very fair thing if the Government, considering how much the nation benefits from the establishment of such colleges, in every case were to contribute a sum proportional to what has been raised in the locality towards the attainment of the obiect.' ....

"We concur to a considerable extent in the opinions expressed by these witnesses. The degree of success which has attended the College of Physical Science at Newcastle-upon-Tyne, both in the collection of local subscriptions and in the organisation of its system of instruction, leads us to express with confidence the hope that by further efforts of the same kind it will before long be placed in a position to establish its claim to assistance from the State."

With regard to the Catholic University of Ireland, while the Commission believes that it is calculated to do much good to the cause of scientific education, it cannot recommend Government to grant it any endowment.

"On a review of the evidence," the Report states, "we are satisfied that the establishment of the Scientific Faculty of the Catholic University has not been without advantage to the instruction of the Irish people, an advantage which might be considerably increased if this faculty could be more completely organised, and its professors increased in number and supplied with adequate means for practical teaching. And we have not failed to observe that at the present time fresh efforts are being made by the persons interested in this institution, to improve and to render more widely available the instruction afforded by it.

"It is also inclisputable that the Catholic University has received, and still continues to receive, a large amount of pecuniary support. The permanency, however, of this support, which proceeds, to a large extent at all events, from annnal subscriptions levied by clerical agency, cannot be predicted with any certainty.

"The peculiar organisation of this institution," the Report concludes, "the religious restrictions imposed upon the selection of scientific professors and lecturersrestrictions the removal of which it would be idle to anticipate; the incompleteness of a large portion of its arrangements for the teaching of science, and the uncertainty of its income, preclude us from recommending that it should receive a grant from public funds."

The general outcome, then, of the Fifth Report of the Science Commission is, that University and King's Colleges, London, and Owens College, Manchester, ought certainiy to receive assistance from Government, that the Newcastle College is in a fair way to prove that it deserves such assistance, and that it would not be advisable to subsidise the Catholic University of Ireland, as it is at present constituted.

J. S, K.

\section{THE APPLICATION OF THE LAWS OF SELECTION TO AGRICULTURE}

$\mathrm{T}$ every phase of life the law of selection comes into play. At one time it is natural, at another time it is more or less artificial. At every time, and in every place, we see evidence of the plastic character of the materials on which the vital principle operates.

In devoting my holidays to an agricultural tour in England this season, I have visited several seed-growers who are conferring great advantages on the public by careful selection of parent plants. I can speak on this point with the experience which a wide range of observation gives. I have myself, by selection, doubled the quantity of solid matter in turnips, and nearly doubled the number of seeds in ears of wheat.

If the principle of selection were universally applied with skill and care in the raising of our seed corn, what an enormous increase would thereby be made to the wealth of the agricultural classes of Great Britain and Ireland!

In our agricultural live stock a series of results, which are truly marvellous, have been accomplished by selection. And yet the principle is understood or practised only by a very small percentage of our farmers.

If any reader wishes to understand in a general way the change that has been made within the last quarter of a century, which is the measure of the life-time of the Royal Agricultural Society of England, let him take the Society's prize lists of 1839 and 1874 . In the interval, several new breeds of sheep and cattle have come to be recognised as having distinct types. Nature has had her share in the work. The soil and climate of every district impress certain characters and qualities on the animal; and, in his artificial selection, the farmer preserves these in whole or part. In studying, some years ago, the origin of the older breeds, I was much struck with the extent to which their distinctive characters were due to the natural conditions under which they rose. And in a recent inquiry into the history of the newly-established breeds, the same leading truth has become still plainer.

To give point to this short paper I derive an illustration from the influence exercised on the art of sheep-breeding by the remarkable change which, common observation tells us, has taken place in the material of garments in com. mon use. I refer to the well-known fact that tweeds and coarse cloths are now much more commonly used than in the last generation. Te meet the demand thus created the farmer has produced sheep which carry wool of longer staple than the old breeds.

My argument is well illustrated in the great plains in the west of Ireland, where the flock-owners have established a splendid new breed, called the Roscommon Sheep. In the production of this variety the breeder has of course exercised his skill in selection. He crossed Leicester tups of the very best English strains of blood with the native ewe ; and he repeated this over and over again until he obtained an animal of the type which suited him. Nature aided him in his art. It may be safely asserted that some of the peculiarities of the wool, as well as some of the peculiar conformations of the body, have been the work of Nature. And it is in retaining what was so well done by Nature that the highest skill is manifested. In England the best example of the argument is possibly afforded by the Lincoln breed of sheep, which stands so deservedly high in public estimation, affording as it does great weight of carcase with a remarkably heavy fleece of lustrous wool. Then, again, let us take the dark-shaded breeds-South Down, Shropshire Down, Oxford Down, and Hampshire Down. The South Down used to be more popular than it is now. It has been giving way in many places to an animal with a larger frame and with a fleece longer in the staple. The first that arose to displace it was the Shropshire, which has been followed by the Oxford Down. Each of these breeds 
pays best under a given set of circumstances; and this only shows the wide field open to British farmers for profiting by the laws of selection.

I look to the development of this great principle as one of the soundest and surest means of promoting the interests of the agricultural classes.

\section{THOMAS BALDWIN}

\section{DARWIN'S "CORAL REEFS"}

The Structure and Distribution of Coral Reefs. By Charles Darwin, M.A., F.R.S., \&c. Second edition, revised. 1874 ; pp. 268 . (Smith, Elder, and Co.)

r THE rising generation of naturalists and geologists 1 has not had, and most probably will never have, such feelings of intellectual pleasure as fell to the lot of the first readers of Charles Darwin's book on Coral Reefs, which was offered to science more than thirty years since. The recent researches into the nature of the deposits of the deep sea, and the discoveries of the bathymetrical zones of water of very different temperatures, are certainly full of vast interest, and will afford the data for the development of many a theory ; but the clear exposition of facts, and the bold theory which characterised the book on Coral Reefs, came unexpectedly and with overpowering force of conviction. The natural history of a zoophyte was brought into connection with the grandest phenomena of the globe-with the progressive subsidence of more or less submerged mountains, and with the distribution of volcanic foci. The forces of the organic and inorganic kingdoms were shown to unite in the production of those circular growths of coral which appeared to rise from profound oceanic depths; and it was made evident that the existence and persistent growth of fragile Porites and Madreporce were dependent upon movements of the crust of the globe, the result of forces acting almost from the beginning-upon movements so vast, equable and slow, that over thousands of square miles the coral grew upwards, whilst the supporting rock, its base, and the mother crust subsided in a wonderful unison. The pristine condition of the globe was in fact brought in relation with the formation of those beautiful islands, the theme of romance and poesy, the delight of the missionary, the dread of the navigator, and which should be, according to Dana, the luxurious home of enervated and used-up investigators.

The theory of the formation of barrier reefs and atolls is stated with Darwin's usual lucidity:- "From the limited depths at which reef-building polypifers can flourish, taken into consideration with certain other circumstances, we are compelled to conclude that both in atolls and barrier reefs the foundation to which the coral was primarily attached has subsided; and that during this downward movement the reefs have grown upwards." "There is not one point of essential difference between encircling barrier reefs and atolls; the latter enclose a simple sheet of water; the former encircle an expanse with one or more islands rising from it. Remove the central land, and an annular reef like that of an atoll in an early stage of formation is left." It was necessary, in order that this theory should be valid, that the depth at which reef-building corals can exist below the surface should be ascertained, and also that direct or indirect proofs of subsidence over a vast area should be offered. The nature of the bottom of the sea immediately surrounding Keeling atoll was carefully examined, and moreover soundings with the wide bell-shaped lead, with tallow armings, were carefully taken, off the fringing reefs of Mauritius. In Keeling atoll outside the reef it was found, "to the depth of ten or twelve fathoms the bottom is exceedingly rugged and seems formed of great masses of living coral, similar to those on the margin. The arming of the lead here invariably came up quite clean, but deeply indented, and chains and anchors which were lowered in the hopes of tearing up the coral were broken." "Between $I 2$ and 20 fathoms the arming came up an equal number of times smoothed with sand and indented with coral ; an anchor and lead were lost at the respective depths of 13 and $I 6$ fathoms. Out of twenty-five soundings taken at a greater depth than 20 fathoms, every one showed that the bottom was covered with sand." Off the reef at Mauritius, "from 15 to 20 fathoms, the bottom was with few exceptions either formed of sand or thickly coated with Seriatopora (one of the Tabulata). At 20 fathoms one sounding brought up a fragment of Madrepora which I believe to be the same species as that which mainly forms the upper margin of the reef ; if so, it grows in depths varying from o to 20 fathoms. Between 20 and 23 fathoms I obtained several soundings, and they all showed a sandy bottom with one exception at 30 fathoms, when the arming came up scooped out as if by the margin of a large Caryophyllia." "The circumstance of the arming having invariably come up quite clean when sounding within a certain number of fathoms off the reef of Mauritius and Keeling atoll (8 fathoms in the former case and $\mathrm{I} 2$ in the latter), and of its having always come up (with one exception) smoothed and. covered with sand when the depth exceeded 20 fathoms, probably indicate a criterion by which the limiting of the vigorous growth of coral might in all cases be ascertained."' Darwin admits that this limit might be exceptionally transgressed, but insists upon the importance of the gradual change, as depth pro. gresses, from living clean coral to a smooth sandy bottom, in endeavouring to fix the depth at which the reef-builders can grow.

Even at this period of Darwin's life, the importance of the struggle for existence had been recognised by him, and had influenced his thoughts. He remarks that "we can understand the gradation only as a prolonged struggle against unfavourable conditions." All subsequent investigations by many independent observers have proved the correctness of this bathymetrical limit of the flourishing of reef-builders, and of late years the general characters of the coral which can exist at a greater depth and even on oceanic floors have been shown to differ essentially from those of the forms which live and flourish amidst the rush of the wave and surf. Darwin notices that where the sea is very shallow, as in the Persian Gulf and in parts of the East Indian Archipelago, the reefs lose their fringing character and appear as separate and irregularly scattered patches, often of considerable area. Around the Philippines the bottom of the sea is "entirely coated by irregular masses of coral, which, although often of large size, do not reach the surface and form reefs." There are huge clumps of Porites and many sponges on the floor of the sea off Cuba, but although 